[Aus dem königl. preuss. Institut für Serumforschung u. Serumprüfung.] (Director: Geh. Med.-Rath Prof. Dr. P. Ehrlich.)

\title{
Ueber Tetanolysin.
}

Von

Thorvald Madsen.

Nachdem Ehrlich den grossen Werth der Reagensglasversuche für das Studium der Toxine und Antitoxine gezeigt hatte, hat diese Versuchsanordnung nach und nach eine immer grössere Bedeutung gewonnen. Die bisherigen Versuche, die die principiell wichtigen Thatsachen feststellten, haben sich allerdings nur auf Gifte nichtbakteriellen Ursprungs, Ricin, Crotin, Cobragift und das hämolytische Aalserum erstreckt. Es erschien deshalb erwünscht, dieselben auch auf Bakteriengifte auszudehnen, nachdem Ehrlich in den Culturen des Tetanusbacillus ein zu Reagensglasversuchen geeignetes hämolytisches Toxin gefunden hat. ${ }^{1}$

Diese hämolytisch wirkende Substanz ist nicht identisch mit jenem Gifte des Tetanusbacillus, das die bekannten Erscheinungen der tetanischen Contractur bei Thieren herrorbringt. Dass beide Gifte - das Tetanolysin und das Tetanospasmin - verschieden sind, ergiebt sich aus folgenden Beobachtungen Ehrlich's:

1. Beide Giftwirkungen erscheinen in versehiedenen Präparaten (Ammoniumsulfatfällung einer Tetanusbouilloncultur) nicht in dem gleichen Verhältniss; es giebt Gifte, die eine stark tetanisirende und eine geringe hämolytische Wirkung haben, und solche, die sich umgekehrt verhalten.

1 Gesellschaft der Charité-Aerzte (Sitzang 3. Februar 1898). Berliner klinische Wochenschrift. 1898. Nr. 12. 
2. Die Haltbarkeit der beiden Gifte ist verschieden, indem in einer Giftlösung die hämolytische Function viel rascher sich abschwächt als die tetanisirende, und zwar sowohl spontan als auch durch künstliche Einwirkungen, z. B. Erhitzung auf $50^{\circ}$ während 20 Minuten.

3. Beide Gifte haben versehiedene Bindungsverhältnisse. Bringt man eine Lösung von Tetanusgift mit rothen Blutkörperchen zusammen, so wird der grösste Theil des Tetanolysins von den rothen Blutkörperchen gebunden, während das Tetanospasmin in Lösung bleibt.

4. Jedem der beiden Gifte kommt ein besonderes Antitoxin zu. Untersucht man verschiedene Tetanussera, die durch Immunisirung von Thieren mit dem beide Gifte enthaltenden Rohgifte erhalten sind, so findet man, dass ihre neutralisirende Wirkung dem Tetanalysin und dem Tetanospasmin gegenüber nicht parallel geht. So fand Ehrlich in einem besonders markanten Fall, dass ein Serum; das stark antispastisch war, fast gar nicht antilytisch wirkte.

Aus diesen hier angeführten Beobachtungen Ehrlich's ergiebt sich mit Sicherheit, dass das Tetanolysin und das Tetanospasmin verschiedenartige Gifte darstellen.

Dies Tetanolysin musste als ein ausserordentlich geeignetes Gift erscheinen, um verschiedene theoretische Fragen zu untersuchen. Einerseits boten die einfachen und leicht in ihre einzelnen Factoren zu zerlegenden Verhältnisse im Reagensglas günstige Gelegenheit, auf die Wirkungsweise des Giftes einzugehen, andererseits erschien es naheliegend, der Frage nach der Existenz $\nabla$ on Toxoiden des Tetanolysins näherzutreten. Schien doch eine Bearbeitung dieser Frage, deren Beantwortung für das Diphtheriegift viele mühevolle und kostspielige Thierversuche erfordert hatte, ${ }^{1}$ als eine relativ einfache Aufgabe für den Reagensglas versuch.

\section{Untersuchung der Giftwirkung des Tetanolysins.}

Ich verwandte zu den Versuchen ein Tetanusgift, das durch Ausfällung einer Tetanusbouilloncultur mit Ammonsulfat in der gewöhnlichen Weise hergestellt war. Das Gift war von mässiger Stärke in seiner Wirkung auf Thiere, indem ungefähr $0.000001 \mathrm{grm}$ die tödtliche Dosis für

1 Ehrlich, Die Werthbestimmung des Diphtherieheilserums. Klin. Jahrbuch. 1897. - Ueber die Constitution des Diphtheriegiftes. Deutsche med. Wochenschrift. 1898. - Th. Madsen, Om Difterigiftens Konstitution. Oversigt over det Kgl. Danske Vidensk. Selskabs Forhandl. 1899. - La constitation du poison diphtérique. Ann. de l'Institut Pasteur. 1899. 
Tabelle I.

\begin{tabular}{|c|c|c|c|}
\hline \multirow{2}{*}{$\begin{array}{l}\text { Nummèr } \\
\text { des Glases }\end{array}$} & \multicolumn{2}{|c|}{ Zugesetzte Giftlösung } & \multirow{2}{*}{$\begin{array}{l}\text { Auflösung der Blutkörperchen } \\
\text { nach } 24 \text { Stunden }\end{array}$} \\
\hline & Concentration & Menge in ccm & \\
\hline 1 & \multirow[t]{13}{*}{1 Procent } & 1,2 & \multirow{9}{*}{$\begin{array}{l}\text { Vollständige Auflösung d. Blutkörperchen. } \\
\text { Die Flüssigkeit ist vollkommen lackfarben, } \\
\text { von gleichmässig dunkelrother Farbe. } \\
\text { In der unteren Schicht der Flüssigkeit } \\
\text { eine schwache Trübung von ungelösten } \\
\text { Blutkörperchen. }\end{array}$} \\
\hline 2 & & $1 \cdot 0$ & \\
\hline 3 & & 0.8 & \\
\hline 4 & & 0.7 & \\
\hline 5 & & 0.6 & \\
\hline 6 & & 0.5 & \\
\hline 7 & & 0.4 & \\
\hline 8 & & 0.35 & \\
\hline 9 & & 0.8 & \\
\hline 10 & & 0.25 & \multirow{4}{*}{$\begin{array}{l}\text { Die Menge der ungelösten rothen Blut } \\
\text { körperchen nimmt zu; nach und nach er- } \\
\text { scheint ein deutlicher Bodensatz. Die oben- } \\
\text { stehende Flüssigkeitssäule ist stets von } \\
\text { derselben gleichmässig dunkelroth. Farbe. }\end{array}$} \\
\hline 11 & & 0.2 & \\
\hline 12 & & 0.17 & \\
\hline 13 & & $0 \cdot 13$ & \\
\hline 14 & \multirow[t]{12}{*}{ 1/10 Procent } & $1 \cdot 0$ & \multirow{8}{*}{$\begin{array}{l}\text { Die oberste Schicht der Flüssigkeit ist in } \\
\text { der Ausdehnung von } 1 \text { cem heller gefärbt } \\
\text { als die übrige Flüssigkeit. } \\
\text { Diese obere Zone wird heller und gewinnt } \\
\text { an Ausdehnung. }\end{array}$} \\
\hline 15 & & 0.8 & \\
\hline 16 & & $0 \cdot 7$ & \\
\hline 17 & & 0.6 & \\
\hline 18 & & 0.5 & \\
\hline 19 & & $0 \cdot 4$ & \\
\hline 20 & & $0 \cdot 35$ & \\
\hline 21 & & $0 \cdot 3$ & \\
\hline 22 & & 0.25 & Farbennuance $1 / 80$. \\
\hline 23 & & 0.2 & Die untere Schicht d. Flüssigk. wird heller. \\
\hline 24 & & $0 \cdot 17$ & \\
\hline 25 & & $0 \cdot 13$ & Farbennuance $1 / 120^{\circ}$. \\
\hline 26 & \multirow[t]{10}{*}{$1 / 100$ Procent } & $1 \cdot 0$ & \multirow{4}{*}{$\begin{array}{l}\text { Die Gesammtflüssigkeit ist von gleich- } \\
\text { mässig roth-gelber Färbang; nur unmittel- } \\
\text { bar über dem Bodensatz etwas stärker } \\
\text { roth gefärbt. }\end{array}$} \\
\hline 27 & & 0.8 & \\
\hline 28 & & 0.7 & \\
\hline 29 & & 0.6 & \\
\hline 30 & & 0.5 & \multirow{6}{*}{$\begin{array}{l}\text { Die ganze Flüsssigkeit ist gleichmässig } \\
\text { schwaeh roth-gelb gefärbt. }\end{array}$} \\
\hline 31 & & 0.4 & \\
\hline 32 & & $0 \cdot 35$ & \\
\hline 33 & & 0.3 & \\
\hline 34 & & 0.25 & \\
\hline 35 & & 0.2 & \\
\hline 36 & \multicolumn{2}{|c|}{ Controle (ohne Giftzusatz) } & \\
\hline
\end{tabular}


eine Maus ron $15^{\mathrm{grm}}$ darstellte. Das Gift löst die Blutkörperchen des Kaninchens, der Ziege, des Hammels, des Pferdes und anderer Thiere. Besonders empfindlich ist Pferdeblut und Kaninchenblut, relativ gering empfindlich ist das Ziegenblut. Zu den folgenden Versuchen diente ausschliesslich defibrinirtes Kaninchenblat, das mit 0.85procent. Kochsalzlösung zu 5 Procent verdünnt wurde. Ein Reagensglas aus Jenaer Gerätheglas wurde stets mit $15^{\mathrm{cem}}$ dieses Gemisches beschickt. Die hohe Flüssigkeitssäule bietet den Vortheil, dass man die Senkung der Blutkörperchen beobachten und für die Deutung des Versuches verwerthen kann.

Die mit Blut beschiekten Reagensgläser wurden mit verschiedenen Mengen der Giftlösung versetzt, gut gemischt, eine Stunde bei $37^{\circ}$ im Ostwald'schen Wasserbad gehalten und dann über Nacht bei niedriger Temperatur belassen.

Die Erscheinungen, wie sie sich nach 24 Stunden beobachten lassen, wird am einfachsten und übersichtlichsten die Schilderung eines einzelnen Versuches illustriren. (Vgl. Tabelle I.)

In den Reagensgläsern (Nr. 33 bis 35), die die geringste Menge Gift enthalten, sieht man alle rothen Blutkörperchen unbeschädigt am Boden liegen; die obenstehende Flüssigkeit ist vollstāndig wasserklar, ebenso farblos wie die des unerlässlichen Controlröhrehens ohne Giftzusatz. Die folgenden Proben, Glas 30 bis 32, zeigen die erste Spur ron Lösung, nãmlich eine rothgelbe Nuance durch die gan ze Flüssigkeit. Von Glas 29 ab treffen wir ein ganz neues Phänomen. Während der obere Theil der Flüssigkeit dieselbe gleichmässige schwach rothgelbe Färbung wie die früher besprochenen Gläser zeigte, sehen wir oberhalb der Kuppe des Reagensglases eine ca. $2^{\mathrm{ccm}}$ hohe, schwach, aber deutlich rothgefärbte Zone.

Um diese Erscheinung zu' verstehen, muss man bedenken, dass das Tetanolysin, das, wie später gezeigt wird, ziemlich schnell an die rothen Blutkörperchen gebunden wird, wie die meisten Bakteriengifte eine Latenzzeit hat, deren Länge theils von der angewandten Giftmenge, theils von der Temperatur abhängt. Fügt man bei einer Temperatur von $37^{\circ}$ eine grosse Menge Gift zu, so erfolgt die vollständige Lösung sehr rasch, die Blutkörperchen befinden sich im Augenblick der Lösung in gleichmässiger Vertheilung und das Resultat ist eine vollkommen gleichmässige dunkelrothe Färbung der ganzen Flüssigkeit. Vermindert man nun die Giftmenge oder erniedrigt man die Temperatur, bei der der Versuch stattfindet, so geht unmittelbar nach der Zufügung des Giftes nur ein Bruchtheil der rothen Blutkörperchen in Lösung, während bis zur Lösung der übrigen eine gewisse Zeit verstreicht, in der eine Senkung derselben stattfindet. Wenn, um ein ganz abstractes Beispiel zu wählen, die Lösung aller rothen Blutkörperchen unter gegebenen 
Versuchsbedingungen 2 Stunden dauerte, ist es klar, dass ein Blutkörperchen, das im Anfang des Versuches an der Oberfläche der Flüssigkeit sich befand, sich nach diesen 2 Stunden eine gewisse Strecke gesenkt hat und erst dann gelöst wird. In diesem Falle wäre also die obere Zone der Flüssigkeit ganz farblos, und erst die untere gefärbt. Die Höhe dieser oben ungefärbten Zone ist also ein Ausdruck der Senkungs- bezw. Latenzzeit. Sie wird um so geringer, je grösser die angewandte Giftmenge wird, und gleichzeitig wird auch die Farbennuance der unteren Schicht dunkler.

So sehen wir, wenn wir von Glas 29 nach oben gehen, dass die untere rothe Zone immer höher und immer intensiver wird. In Glas 18 bis 20 ist nur die oberste Schicht der Flüssigkeit in der Auslehnung von $1 \mathrm{ccm}$ heller gefärbt, als die übrige Flüssigkeit. Von Glas 17 ist die ganze Flüssigkeitssäule von derselben gleichmässig dunkelrothen Farbe. Zugleich nimmt man wahr, dass die ungelösten Blutkörperchen, die sich vorher leicht zu einem Bodensatz sammelten, sich jetzt lange in der Flüssigkeit schwebend erhalten. Die Menge der ungelösten Blutkörperchen wird in Glas 17 bis 5 immer geringer, und endlich sehen wir in Glas 1 bis 4 vollständige Lösung aller Blutkörperchen.

Um diese Erscheinung richtig zu deuten, muss man sich klar machen, dass man ein gegebenes Blut nicht einfach als aus vollkommen gleichartig beschaffenen rothen Blutkörperchen bestehend sich vorzustellen hat. Da im normalen Blutleben stets rothe Bluthörperchen zerstört und neue gebildet werden, repräsentiren in jedem Blut die Erythrocyten die verschiedensten Altersstufen. ${ }^{1}$ Dementsprechend muss man annehmen, dass Blutkörperchen von sehr verschiedener Resistenz gegenüber verschiedenen Einwirkungen in einem und demselben Blut vorhanden sind und dass eine fortlaufende Scala derselben von den widerstandsfähigsten bis $\mathrm{zu}$ den empindlichsten existirt. Betrachten wir eine Versuchsreihe wie die oben angeführte, so sind es besonders zwei Grenzpunkte, die unsere Aufmerksamkeit auf sich ziehen. Es ist dies die Giftmenge, durch die eine vollständige Lösung erzielt wird und diejenige, bei der eben noch eine Spur von Lösung stattfindet. In letzterem Falle muss man annehmen, dass nur mehr die in recht geringer Zahl vorhandenen, empfindlichsten Elemente zur Lösung gelangen, die auch dem Einfluss geringster Giftmengen in sehr kurzer Zeit erliegen. Jedes rothe Blutkörperchen dieser Art wird an seiner ursprünglichen Stelle gelöst; wahrnehmbar wird diese Lösung natürlich erst, nachdem die Flüssigkeit durch die Senkung der übrigen rothen Blutkörperchen vollständig geklärt ist. Die gleichmässige, diffuse, rothgelbe Färbung, die man in den Gläsern

${ }^{1}$ Ehrlich u. Lazarus, Die Anämie. S. 32. 
Nr. 30 bis 32 wahrnimmt, kann nur auf die Lösung der eben beschriebenen empfindlichsten Blutkörperchen bezogen werden. Wäre dieses nicht der Fall, hätte man auch in diesen Gläsern eine der Senkung entsprechende Zonentheilung gesehen. In Glas 29 sieht man im unteren Theile eine geringe Rothfärbung; hier beginnt also offenbar die Lösung einiger der resistenteren Blutkörperchen, die erst nach einer ziemlich langen Latenzzeit einsetzt, in der die Blutkörperchen eine beträchtliche Senkung erfahren haben. Wenn man nun nach und nach eine immer dunklere Färbung der oberen Zone wahrnimmt, so muss diese auf die Lösung resistenter Blutkörperchen mit sehr kurzer Incubationszeit durch die steigenden Giftdosen bezogen werden.

Mit weiter steigenden Giftmengen werden auch immer resistentere Blutkörperchen zur Lösung herangezogen, bis endlich die Lösung complet wird. Man sieht also, dass für die beiden Endwerthe einer solchen Bestimmung die resistentesten und die empfindlichsten Blutkörperchen entscheidend sind, die sicher nur einen kleinen Procentsatz der Blutkörperchen überhaupt ausmachen.

Die Verhältnisse werden dadurch noch complicirter, dass das Blut verschiedener Kaninchen sich durchaus nicht gleich verhält, sondern dass die Empfindlichkeit im Ganzen bedeutenden Schwankungen unterliegt, so dass die Giftmengen, die bei verschiedenen Blutsorten zur selben Wirkung nöthig sind, um das zwei- bis vierfache voneinander abweichen. Auch das relative Verhältniss der Blutkörperchen verschiedener Empfiudlichkeit unterliegt unabhängig von der Gesammtempfindlichkeit des Blutes Schwankungen. Es zeigte sich, dass die Verschiedenheiten sich nicht gleichmässig auf die obere und untere Grenze erstrecken. Während die untere Grenze der Lösung sich oft ziemlich constant hielt, fand man, dass die obere Grenze (complete Lösung) sehr grossen Schwankungen unterlag.

Wir möchten hier bemerken, dass die Resistenz der rothen Blutkörperchen dem Tetanolysin gegenüber, wie wir sie hier bestimmen, gar keinen Maassstab abgiebt für die Resistenz desselben Blutes anderen Giften gegenüber. Es ist durch Versuche im Institut festgestellt, dass z. B. ein Blut, das dem Tetanolysin gegenüber überempfindlich war, anderen Blutgiften gegenüber - Crotin, hämolytische Sera - normale oder verhältnissmässig geringe Empfindlichkeit zeigte.

Man darf deshalb nicht von einer Resistenz der Blutkörperchen im Allgemeinen sprechen, sondern muss in jedem einzelnen Fall die Resistenz der einzelnen Gruppen rother Blutkörperchen einem Gifte gegenüber bestimmen.

Aus diesen Auseinandersetzungen ergiebt sich, dass man bei der Beurtheilung der Tetanolysinwirkung auf rothe Blutkörperchen diese ein- 
theilen kann in 1. solche von hoher Resistenz, 2. von mittlerer Resistenz, 3. von geringer Resistenz.

$\mathrm{Da}$ es bei den folgenden Versuchen wichtig war, eine Beurtheilung zu finden, die eine genaue Vergleichung aller Versuche zuliess, ergab es sich, dass zu diesem Zweck weder die obere, noch die untere Grenze praktisch verwendbar war. Zunächst ist es recht schwierig, diese Grenzen ganz genau zu bestimmen, und ausserdem erschien es irrationell, eine Bestimmung zu benutzen, bei der man von einer relativ kleinen Menge der rothen Blutkörperchen - der am meisten und der am wenigsten resistenten - abhängig war. Es war vielmehr natürlich, hierzu eine Bestimmung zu benutzen, die auf der grossen Anzahl der Blutkörperchen von mittlerer Empfindlichkeit fusste. Die besten. Dienste leistete dabei ein einfaches colorimetrisches Verfahren. Durch Auflösung bestimmter Mengen Kaninchenblut in einem Wasserglyceringemisch wurden die Farbennuancen hergestellt, mit denen die einzelnen Versuche verglichen wurden. Es zeigte sich, dass man auf diese Weise mit grosser Sicherheit den Auflösungsgrad beurtheilen kann. Bei den folgenden Versuchen dienten zum Vergleich die Farbennuancen, die durch Auflösung von 1 Theil Blut in 60, bezw. in 120 Theilen Flüssigkeit hergestellt wurden und die kurz als $1 / 60$ bezw. $1 / 120$ bezeichnet werden. Namentlich die letzte Farbennuance leistete die besten Dienste. $\mathrm{Da}$ die angewandte Blutverdunnung stets 5 Procent ist, so entspricht die complete Lösung einer Farbennuance $=1 / 20$; die Nuance $1 / 30$ und $1 / 120$ entspricht der Lösung des dritten oder sechsten Theiles der rothen Blutkörperchen.

Die Wirkung des Tetanolysins ist ausserordentlich abhängig von der Temperatur. Vergleicht man die Wirkung des Giftes in 1 Stunde bei $37^{\circ}$ mit darauffolgender Senkung bei ca. $10^{\circ}$ und in 24 Stunden bei $0^{\circ}$ bis $1^{\circ}$, so braucht man bei der letzteren Temperatur ungefähr hundert Mal so viel, um dieselbe Wirkung zu erreichen. Zwischen diesen Temperaturgrenzen finden sich ganz allmähliche Uebergänge.

Es ist nicht allein die absolute Wirkung, die durch die niedere Temperatur herabgesetzt wird, auch die Latenzzeit der Wirkung wird bedeutend grösser. Dies sieht man sehr deutlich an den oben beschriebene Senkungszonen, indem bei niederer Temperatur selbst in den Röhrchen mit sehr starker Lösung die obere Flüssigkeitsschicht in ziemlicher Ausdehnung ganz farblos oder jedenfalls nur sehr schwach gefärbt gefunden wird. 


\section{Die Nentralisationsrerhältnisse des Tetanolysins.}

Für die Erforschung des Diphtheriegiftes und seiner Modificationen (Toxoide) hat das Studium der Neutralisationsverhältnisse zwischen dem Gift und seinem specifischen Antitoxin die wesentlichsten Dienste geleistet. Es erschien daher wünschenswerth, auch für das Tetanolysin diese Beziehungen $\mathrm{zu}$ untersuchen.

Wie schon erwähnt, existiren bedeutende Schwankungen in der Fmpfindlichkeit des Kaninchenblutes dem Gift gegenüber. Es war daher nothwendig, dass gleichzeitig mit den Neutralisationsversuchen eine genaue Bestimmung vorgenommen wurde, um das Verhalten dieses Blutes gegenüber dem Gift allein festzustellen. Diese absolute Giftbestimmung bildete die Grundlage für die Beurtheilung der übrigen Versuche. Wenn sich herausstellte, dass ein Blutgemisch bedeutende Abweichungen von einem gewissen Mittelwerth zeigte, wurde das Blut als über- bezw. unterempfindlich als unbrauchbar erachtet und der Versuch ausgeschaltet. ${ }^{1}$ Man eliminirt ja ebenso aus den entsprechenden Versuchen mit Diphtheriegift Reihen von Versuchsmeerschweinchen, wenn dieselben abnorm reagieren, d. h. überempfindlich oder unterempfindlich sind.

Zunächst wurde der absolute Neutralisationspunlt bestimmt. Als Grundlage für alle Bestimmungen diente eine ganz willkürlich gewählte, constante Menge Tetanusgift, nämlich 2 ccm einer 2 procentigen Lösung des Trockengiftes. Diese Menge stellt ein vierfaches Multiplum der vollkommen lösenden Dosis dar, wäre also im Stande, $60 \mathrm{~cm}$ der 5 procentigen Blutmischung eben noch complet oder $360 \mathrm{cem}$ zur Farbennuance $1 / 120$ in Lösung zu bringen. Diese Lösung in physiologischer Kochsalzlösung wurde stets unmittelbar vor dem Versuche frisch hergestellt und durch Centrifugirung geklärt.

Als Antitoxin wurde ein trockenes Tetanusserum benutzt, das in $1 \mathrm{grm}$ gegenüber dem Tetanospasmin 50 I.-E., welche der staatlichen Controle entsprechen, enthielt; von diesem wurde eine $1 / 2$ procentige Stammlösung in Glycerin-Kochsalzwasser hergestellt. $\mathrm{Zu}$ den Versuchen selbst wurde diese Stammlösung stets zu $1 / 40$ Procent mit physiologischer Kochsalzlösung verdünnt.

Zur vollkommenen Neutralisation (Flüssigkeit farblos) der angegebenen $2^{\mathrm{cem}}$ Gift war 1.3 bis $1.4^{\mathrm{ccm}}$ der $1 / 40$ procentigen Antitoxinlösung nöthig,

1 Das zu den Versuchen dienende Kaninchenblut wurde als von normaler Empfindlichkeit angesehen, wenn 1100 bis $1300^{\circ \mathrm{cm}}$ der 5 procent. Mischung durch Zusatz der constanten Giftmenge $(0.01 \mathrm{~cm} 1$ Procent) unter den üblichen Versuchsbedingungen eine dem sechsten Theil der gesammten Blutkörperchen entsprechende Lösungsnuance zeigte (Farbennuance 1/120). 
Tabelle II.

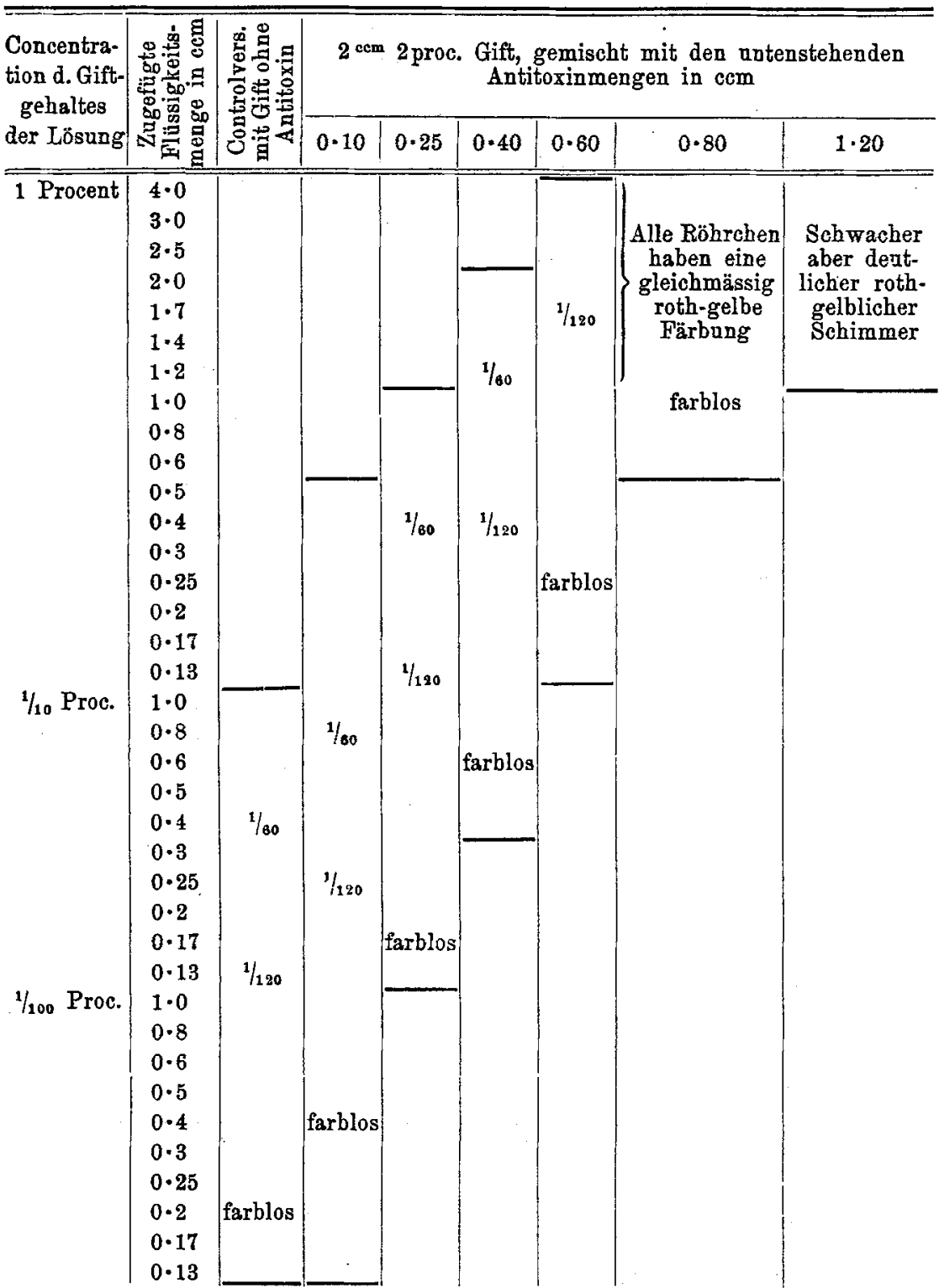

Die wagerechten Striche geben die Grenzen an, innerhalb welcher jeder, der in einer senkrechten Reihe stehenden Versuche ausgeführt ist. Der Uebersichtlichkeit halber sind von den Einzelbestimmungen nar diejenigen angegeben, die für die Messungen von Bedeutung sind. 
vorausgesetzt, dass Gift und Antitoxin 2 Stunden bei Zimmertemperatur gemiseht blieben. Es wurde $0.04 \mathrm{grm}$ des Trockengiftes durch 0.000325 bis $0.00035 \mathrm{grm}$ des festen Antitoxins neutralisiert; 1 Theil Serum neutralisirt also die 120 fache Menge des Giftes.

Zu den folgenden Versuchen wurde hauptsächlich die von Ehrlich angegebene Methode der partiellen Sättigung des Giftes mit Antitoxin angewandt. Es wurden also zu den $2{ }^{\mathrm{cm}}$ Gift weniger als 1.3 bis $1.4^{\mathrm{ccml}}$ zugefügt. Zur genauen quantitativen Feststellung der in solchen ungesättigten Gemischen freien Giftmenge musste stets der Vergleich mit einer reinen Giftlösung derselben Concentration vorgenommen werden. Dies wurde so bewerkstelligt, dass, während ein Theil der 2 procentigen Giftlösung zur partiellen Sättigung mit Antitoxin 2 Stunden bei Zimmertemperatur stehen blieb, die zur Controle nöthige Menge derselben 2 procentigen Giftlösung ohne Antitoxin unter den gleichen Bedingungen verweilte. Nach Verlauf von 2 Stunden wurden beide Lösungen auf 1 Procent Giftgehalt verdünnt und gleichzeitig bestimmte Mengen beider den mit $15 \mathrm{ccm}$ des Blutgemisches gefüllten Reagensgläsern zugefügt. Diese blieben, wie schon erwähnt, genau eine Stunde bei $37^{\circ}$ und dann über Nacht zur Senkung bei niedriger Temperatur. Auf diese Weise konnte der durch die partielle Sättigung bedingte Giftdefect leicht berechnet werden. Vorstehendes Beispiel illustrirt am besten die Versuchsanordnung (rgl. Tab. II).

Aus diesem Versuche ist Folgendes ersichtlich: Fügt man der Giftmenge $0 \cdot 10^{\mathrm{cm}}$ Antitoxinlösung, also nur etwa den 13 . Theil der neutralisirenden Menge zu, so ist jedesmal doppelt so viel von dem Gemisch dem Blute zuzufügen, als ron der Controlgiftlösung, um die gleiche Wirkung wie durch diese zu erhalten. Das Gift hat also die Hälfte seiner Wirkung verloren. Fügt man $0 \cdot 25 \mathrm{~cm}$, also ungefähr den 5 . Theil der neutralisirenden Antitoxinmenge zu, dann benöthigt man zur Erzielung gleicher Lösung wie durch die Controle, $10 \mathrm{Mal}$ so viel als ron dieser. Der Giftdefect beträgt also $9 / 10^{\circ}$ Setzt man $0.40^{\mathrm{cm}}$ der Antitoxinlösung zu, so erhöht man die erforderliche Menge auf das 30 fache, bei $0.60 \mathrm{~cm}$ anf das 100 fache und bei $0.80^{\mathrm{cem}}$ kann man selbst mit der 400 fachen Menge nur eine schwach rothgelbe, quantitativ nicht bestimmbare Lösungsnuance erzielen.

Aus diesen Beziehungen geht hervor, dass das Neutralisationsbild des Tetanolysins ein sehr complicirtes ist. Im entgegengesetzten Fall wären ja die Ergebnisse der partiellen Sättigung ganz einfache, indem die Lösungswirkung genau umgekehrt proportional der zugefügten Antitoxinmenge wäre. So müsste z. B. bei $0.1^{\mathrm{ccm}}$ Antitoxin nicht die Hälfte der Giftwirkung, sondern nur $1 / 13$ verloren sein, bei $0.25 \mathrm{cem}$ nicht $\% / 10$, son-

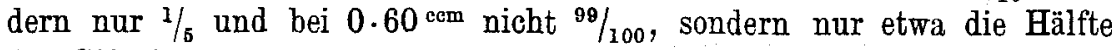
der Giftwirkung. 
Am einfachsten lässt sich dieses Neutralisationsbild wohl graphiseh darstellen in derselben Weise, wie dies Ehrlich für das Diphtheriegift gethan hat.

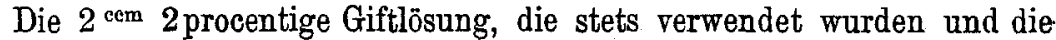
durch $1.30 \mathrm{cem}$ Antitoxinlösung neutralisirt werden, kann man durch ein Diagramm bezeichnen, bestehend aus einer Axe, auf welcher man 130 gleich grosse Ordinaten abträgt, jede entsprechend der Giftmenge, die durch $1 / 130$ der genannten Antitoxinmenge gebunden wird. Es ist also ganz willkürlich, aus. Zweckmässigkeitsgründen, als Einheit diejenige Giftmenge (, 1 Bindungseinheit") gewählt, die durch 0.01 cem unserer Antitoxinlösung neutralisirt wird.

Die einzelnen Bindungseinheiten sind auf der Axe so vertheilt, dass man am meisten rechts diejenigen abgesetzt hat, die am ersten frei werden, wenn man kleinere Mengen Antitoxin, als die vollständig neutralisirende Dosis, verwendet.

Da man in diesem Falle nicht wie beim Diphtheriegift nur einen einzigen Maassstab hat, nämlich die einfach tödtliche Dose, sondern die verschiedenen Lösungsnuancen, farblos, $1 / 120,1 / 80$, complet als Maass wählen kann, so sind dementsprechend auch jedesmal verschiedene Diagramme möglich. Gehen wir zunächst von der Farbennuance $1 / 120$ aus, die in einem Tinctionsgebiet liegt, 'in dem die Unterscheidung feinster Farbendifferenzen am sichersten möglich ist, so können wir das Diagramm folgendermassen darstellen.

Wir wissen, dass $0.13^{\mathrm{cm}}$ der $1 / 10$ procentigen Giftlösung (vgl. Tab. II) 15 cm Blutgenisch zu dieser Farbennuance lösen kann. Folglich kann 1 com 1 procentiger Giftlösung $1150^{\mathrm{cem}}$ Blut zu derselben Farbennuance lösen. Setzen wir zum Gift $0.10^{\mathrm{cem}}$ Antitoxin, so wird von dieser $\mathrm{Mi}$ schung $0.25 \mathrm{~cm} 1 / 10$ Procent für $15 \mathrm{ccm}$ Blut nöthig sein; 1 cem 1 Procent wird also nur $600^{\mathrm{ecm}}$ Blut zur Nuance $1 / 120$ lösen können. Duroh Zusatz von $0.1 \mathrm{~cm}$ Antitoxin (10 Bindungseinheiten entsprechend) hat also 1 com 1 Procent Giftlösung die Fähigkeit verloren, $550 \mathrm{~cm}$ Blutverdünnung zu $1 / 120$ zu lösen. Jeder dieser 10 Bindungseinheiten entspricht demnach durchschnittlich die Fähigkeit, $55^{\mathrm{cm}}$ Blut in der angeführten Weise zu lösen. Ist statt $0 \cdot 10^{\mathrm{cm}} 0.25 \mathrm{~cm}$ Antitoxinlösung zugefügt, so verliert das Gift $\% / 10$ seiner ursprünglichen Wirkung. $1^{\mathrm{ccm}} 1$ Procent von dieser Mischung kann nur mehr $115^{\mathrm{ccm}}$ Blut lösen. Durch Zufügung von 15 Bindungseinheiten Antitoxin hat das Gift also noch weiter die Lösungsfähigkeit für $485^{\mathrm{cem}}$ Blut verloren. Von diesen Bindungseinheiten entspricht also jeder die Fähigkeit, $32 \mathrm{~cm}$ Blut zu lösen. Auf dieselbe Weise berechnen sich die Zahlen bei den übrigen Antitoxindosen. Setzen wir $0.80^{\mathrm{cm}}$ und mehr $\mathrm{zu}$, so erhalten wir überhaupt, selbst mit sehr grossen 
Tabelle III.

\begin{tabular}{|c|c|c|c|c|}
\hline $1^{\mathrm{ccm}} 1$ Procent ron & 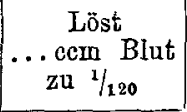 & Differenz & $\begin{array}{l}\text { Entspricht } \\
\text { Bindungs- } \\
\text { eigheiten }\end{array}$ & $\begin{array}{l}\text { Jede Bindungseinheit } \\
\text { löst durchschnittlich } \\
\text {...cem Blut zu 1/120 }\end{array}$ \\
\hline $\begin{array}{l}\text { Vollgift } . \\
\Rightarrow+0.100 \mathrm{cos} \text { Ant. } \\
"+0.25, " \\
"+0.40, " \\
"+0.60, "\end{array}$ & $\begin{array}{r}1150 \\
600 \\
115 \\
\text { ca. } 38 \\
\text { ca. } 9\end{array}$ & $\begin{array}{r}550 \\
485 \\
77 \\
29\end{array}$ & $\begin{array}{l}10 \\
15 \\
15 \\
20\end{array}$ & $\begin{array}{c}55 \\
32 \\
\text { ca. } 5 \\
\text { ca. } 1 \cdot 5\end{array}$ \\
\hline
\end{tabular}

Graphisch ausgeführt stellen sich diese Verhältnisse folgendermassen dar: (s. Fig. 1.)

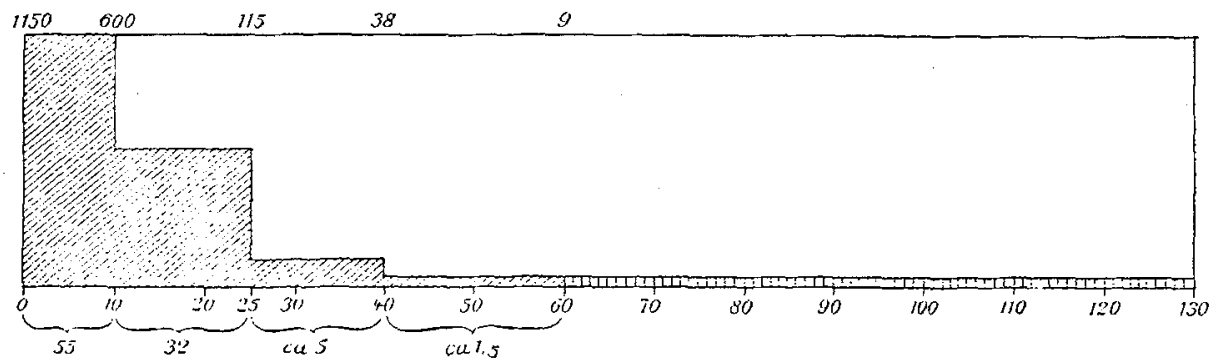

Die letzte Zahlenreibe entspricht der durchschnittl. Wirkung von jeder Bindungseinheit.

Fig. 1.

Mengen, keine Lösung mehr, die $1 / 120$ entspricht. Hier haben wir es also entweder mit sehr geringen Giftmengen zu thun oder aber mit einem Gift von so geringer Wirkungsfähigkeit, dass sie überhaupt nicht in der gewöhnlichen Weise gemessen werden kann. Die angeführten Zahlen können in folgender Weise tabellariseh aufgezeichnet werden. (Vgl. Tab. III.)

Die ersten zehn am weitesten nach links stehenden Bindungseinheiten des Giftes, die am ersten gebunden werden, haben durchsehnittlich je eine Wirkung, die man mit der Zahl 55 ausdrücken kann und die man durch Absetzen von 55 willkürlich gewählten Ordinateneinheiten bezeichnen kann. Die Wirkungsfähigkeit der folgenden 15 Bindungseinheiten ist im Durehsehnitt $=32$ und dieselben können durch eine entsprechende Zahl von Ordinateneinheiten wiedergegeben werden u. s. w.

Eine sehr grosse Zahl von Versuchen zeigte, dass man ganz dieselbe Vertheilung des Giftes erhält, gleichgiltig ob man zum Vergleich stärkere Farbennuancen $(1 / 80$ ) oder den Nullpunkt (farblos) wählt. Führte man die Versuche mit partieller Sättigung mit kleineren Intervallen, als den hier 
angegebenen, aus, so konnte man zeigen, dass die.Wirkung des Giftes zwischen den Ordinaten 10 und 25 gleichmässig abfällt (s. z. B. Figg. 3 u. 4). Die Wirkung des Tetanolysins ist wahrscheinlicher Weise im Diagramm durch eine von links nach rechts eben sinkende Curve darzustellen. Der Theil des Giftes, der zwischen ca. 60 und 130 liegt, besitzt nur die Fähigkeit, die schon beschriebene gleichmässige schwach

Tabelle IV.

Nach $1 / 2$ Stunde.

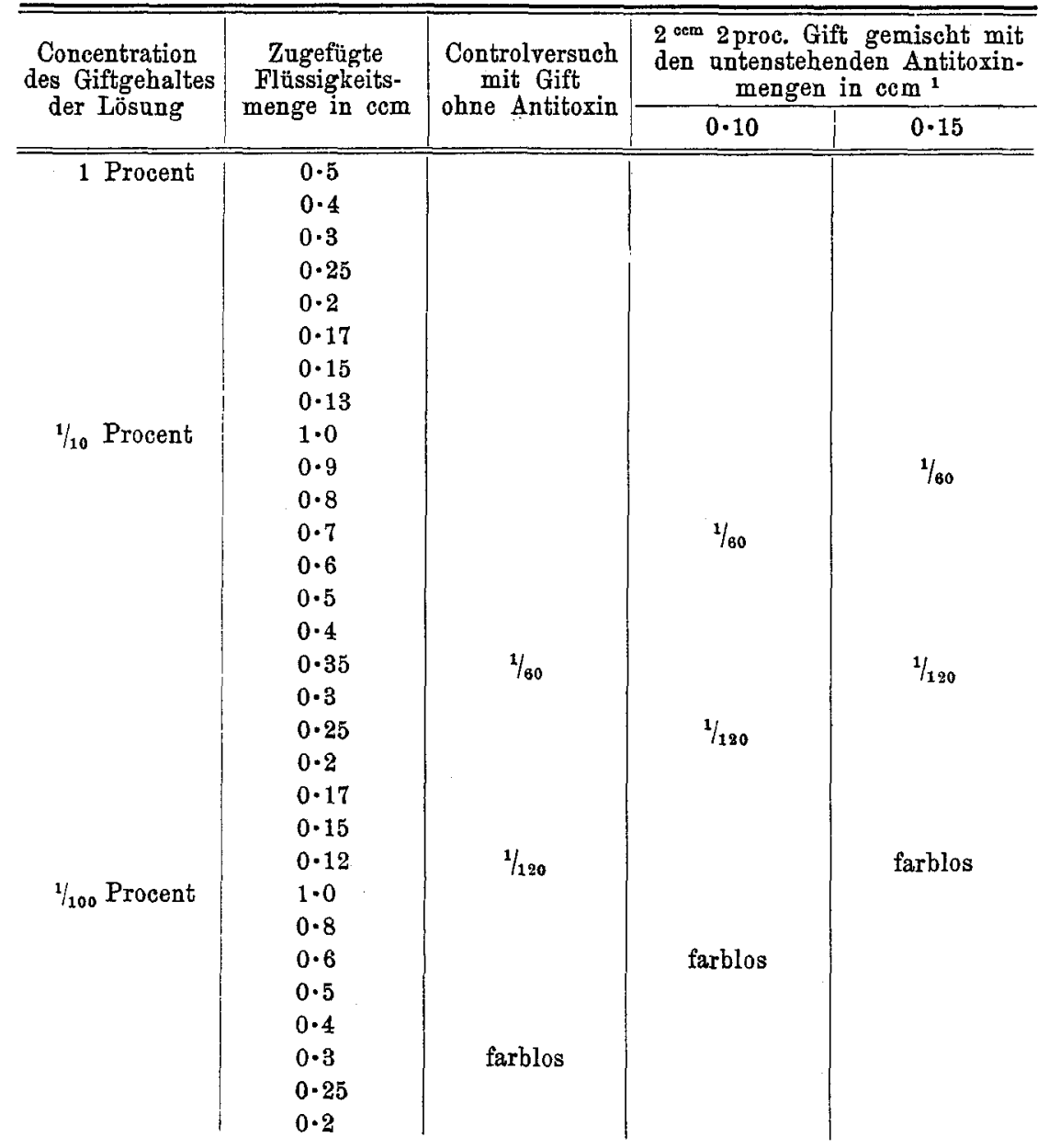

1 Der Uebersicht halber sind die Verhältnisse zwischen Gift und Antitoxin in diesem und dem folgenden Versuch in den früher benutzten Concentrationen (2 Proc. Gift, 1/40 Proc. Antitoxin) angegeben. 
ÜBer TeTanoursin.

Nach 5 Stunden.

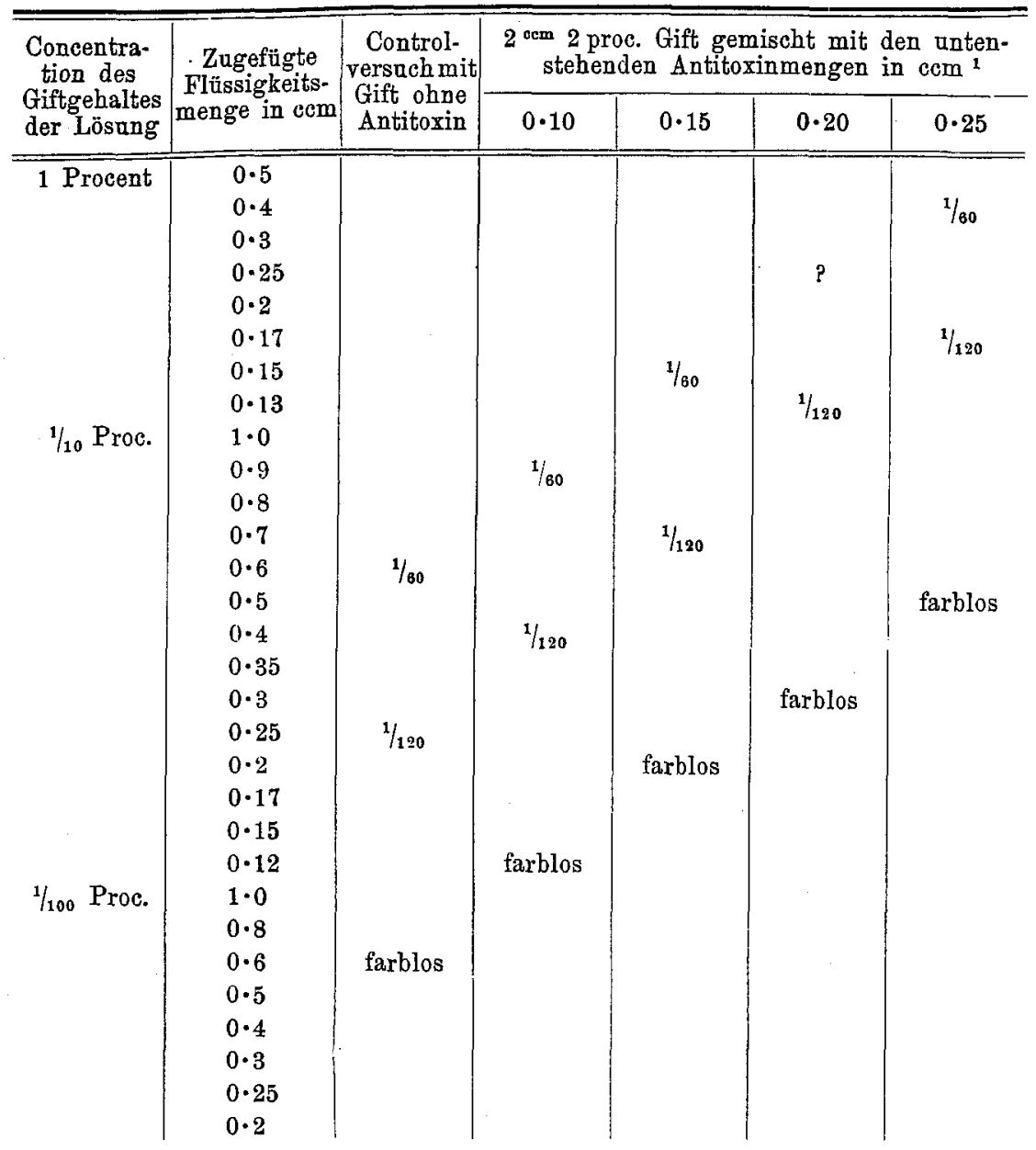

rothgelbe Färbung zu erzeugen. Man muss deshalb annehmen, dass dieser Theil des Giftes nur im Stande ist, die am wenigsten resistenten Blutkörperchen zu lösen.

Das Tetanolysin ist ausserordentlich labil. In dünnen Lösungen (z. B. ${ }^{1 / 10}$ Procent in physiologischer Kochsalzlösung) wird es bei Zimmertemperatur schon in weniger als einer Stunde erheblich abgeschwächt. Selbst concentrirte Lösungen, z. B. 4 Procent, werden bei ca. $20^{\circ}$ in 5 Stunden bis zur Hälfte und in 24 Stunden bis zum ca. 15. Theil der

1 Vgl. Anmerkung auf voriger Seite. 
Tabelle V. Resumé.

Nach ${ }^{1} f_{2}^{-}$Stunde.

\begin{tabular}{|c|c|c|c|c|}
\hline 1 cem 1 Procent von & $\mid \begin{array}{cc}\text { Löst .... ccm } \\
\text { Blat za } & 1 / 120\end{array}$ & Differenz & $\begin{array}{l}\text { Entspricht } \\
\text { Bindungs- } \\
\text { einheiten }\end{array}$ & $\begin{array}{l}\text { Jede Bindungs- } \\
\text { einheit löst } \\
\text { durchschnittl.... } \\
\text { ecm Blut zu } 1 / 120\end{array}$ \\
\hline $\begin{array}{c}\text { Vollgift }+. .+. \\
\qquad \quad+0.10 \text { com Ant. } \\
\Rightarrow \quad+0.15, ",\end{array}$ & $\begin{array}{r}1250 \\
600 \\
428\end{array}$ & $\begin{array}{r}\quad 650 \\
>\quad 172\end{array}$ & $\begin{array}{r}10 \\
5\end{array}$ & $\begin{array}{l}65 \\
34\end{array}$ \\
\hline
\end{tabular}

Nach 5 Stunden.
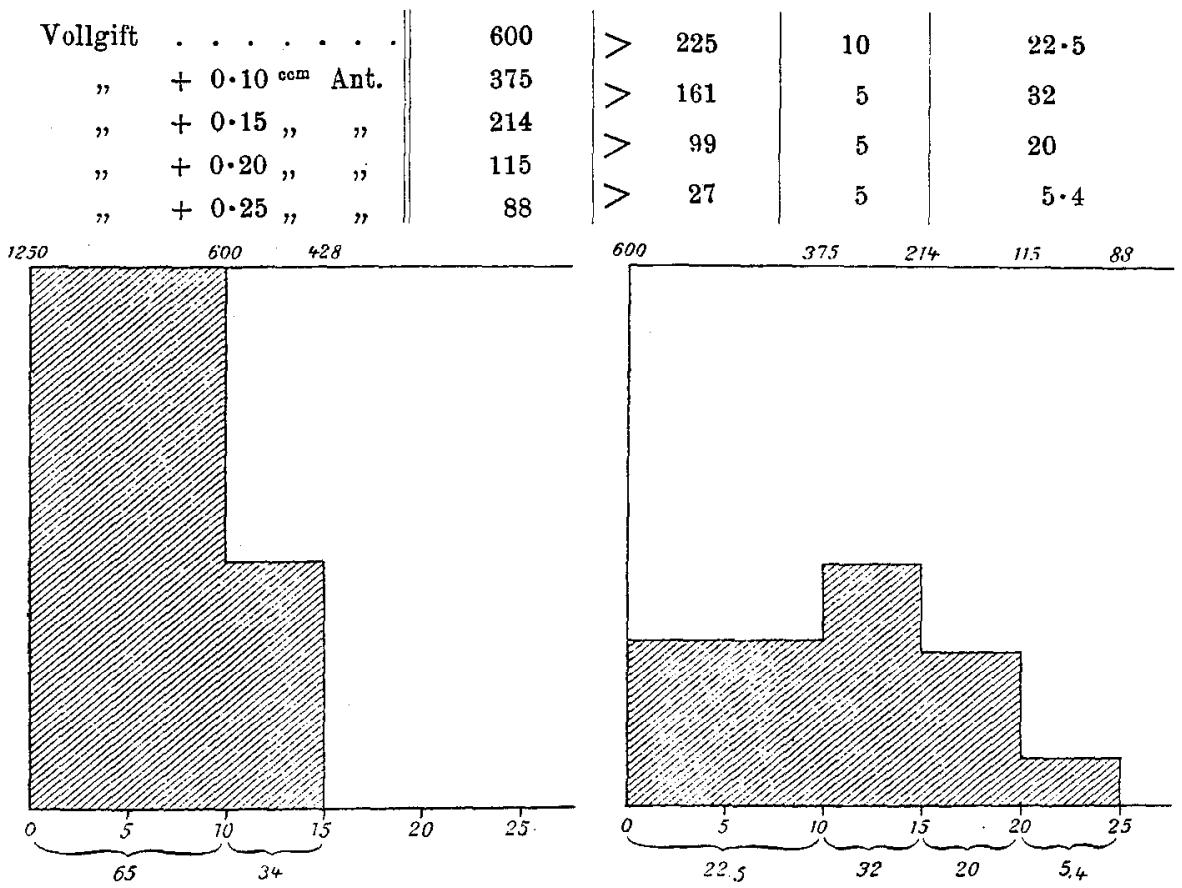

Die letzte Zahlenreihe entspricht der durchschnittl. Wirkung von jeder Bindungseinheit. Fig. 2.

Fig. 3.

Wirkung abgeschwächt. Der Versuch Tab. IV zeigt dies. Werden die concentrirten Lösungen dagegen in Eis in wohl verkorkten Flaschen aufbewahrt, behalten sie ihre Stärke unverändert, jedenfalls 24 Stunden. In trockenem Zustand ist das durch Ammonsulfat gefällte Gift sehr stabil.

Durch eine Reihe ron Versuchen liess sich feststellen, dass bei dieser Abschwächung nicht das ganze Gift gleichmässig angegriffen wurde, wie aus den Tabellen IV u. $\mathrm{V}$ hervorgeht. Die Versuche sind so angestellt, dass von Gift und Antitoxin eine doppelt so concentrirte Lösung als früher 
angewandt wurde, nämlich eine 4 procentige Gift- und eine $1 / 20$ procentige Antitoxinlösung, um eine möglichst schnelle und vollständige Bindung zu erzielen. Nachdem das Gift-Antitoxingemisch $1 / 2$ Stunde bezw. 5 Stunden bei $20^{\circ}$ gehalten war, wurde dasselbe untersucht und gleichzeitig eine 4 procentige Giftlösung, die unter den gleichen Bedingungen aufbewahrt war. (Vgl. Tab. IV u. V und Figg. 2 u. 3.)

Man sieht, dass die Abschwächung hauptsächlich in dem Theil des Giftes stattgefunden hat, der den ersten Bindungseinheiten entspricht, während der übrige Theil in viel geringerem Maasse geändert ist. Dies sieht man deutlich bei Vergleich der Figg. 2 und 3. Im Bereich der zehn ersten Bindungseinheiten ist also $2 / 3$ des Giftes in eine ungiftige Modification verwandelt, während die Fähigkeit, Antitoxin zu binden, keine Veränderung erlitten hat. Es hat hier offenbar ganz derselbe Vorgang stattgefunden, den Ehrlich bei der Abschwächung des Diphtheriegiftes beschrieben und als Toxoidbildung bezeichnet hat. Wenn die Aufbewahrung des Giftes sich aber auf 24 Stunden erstreckte, wobei also die Giftwirkung bis auf $1 / 15$ abgeschwächt wurde, dann zeigte sich, dass alle Theile des Giftes in ungefähr demselben Naasse abgeschwächt waren: (Vgl. Tab. VI u. VII und Figg. 4 u. 5.)

Die eigenthümliche Abschwächung der ersten Bindungseinheiten des Giftes zeigt eine grosse Analogie mit dem Verhalten des Diphtheriegiftes. Wie es hier der Fall ist, verliert das "Prototoxin" viel eher seine toxischen Eigenschaften, als das stabilere „Deuterotoxin“. Wenn man die für das Diphtheriegift gewählten Bezeichnungen auf das Tetanusgift übertragen will, könnte man denjenigen Theil des Giftes, der den Ordinaten 1 bis 10 entspricht, als Prototoxin, die resistenteren und relativ stark wirkenden Theile zwischen 10 und 25 als Deuterotoxin, die schwächer, aber noch deutlich wirksamen Theile zwischen 25 und 60 als Tritotoxin und endlich die äusserst schwach und nur auf die empfindlichsten Blutkörperchen wirkenden Ordinaten von 60 bis 130 als Toxon bezeichnen.

Die obeng:nannten Versuche gaben auch Aufschluss darüber, ob entsprechend der Absehwächung der Giftigkeit auch die Bindungsfähigkeit sich vermindert. Man sah, dass dieses nicht der Fall war, da nach Zufügung von 1.0 und 1.1 Antitoxin noch deutliche Lösung stattfand.

Durch diese Beobachtungen wird man za derselben Auffassung wie für das Diphtheriegift geführt, dass nämlich die toxischen und die antitoxinbindenden Eigenschaften des Giftes auf zwei rerschiedene Gruppen, eine toxophore und eine haptophore, zu beziehen sind. Auch für das Diphtheriegift ergab sich diese Anschauung daraus, dass die Toxicität des Giftes sehr bedeutend sinken kann, ohne dass die antitoxinbindende Kraft nur im geringsten vermindert ist (Ehrlich, Verf.). 
Thorpaid Madsen:

Tabelle VI.

Nach 1/2 Stunde.

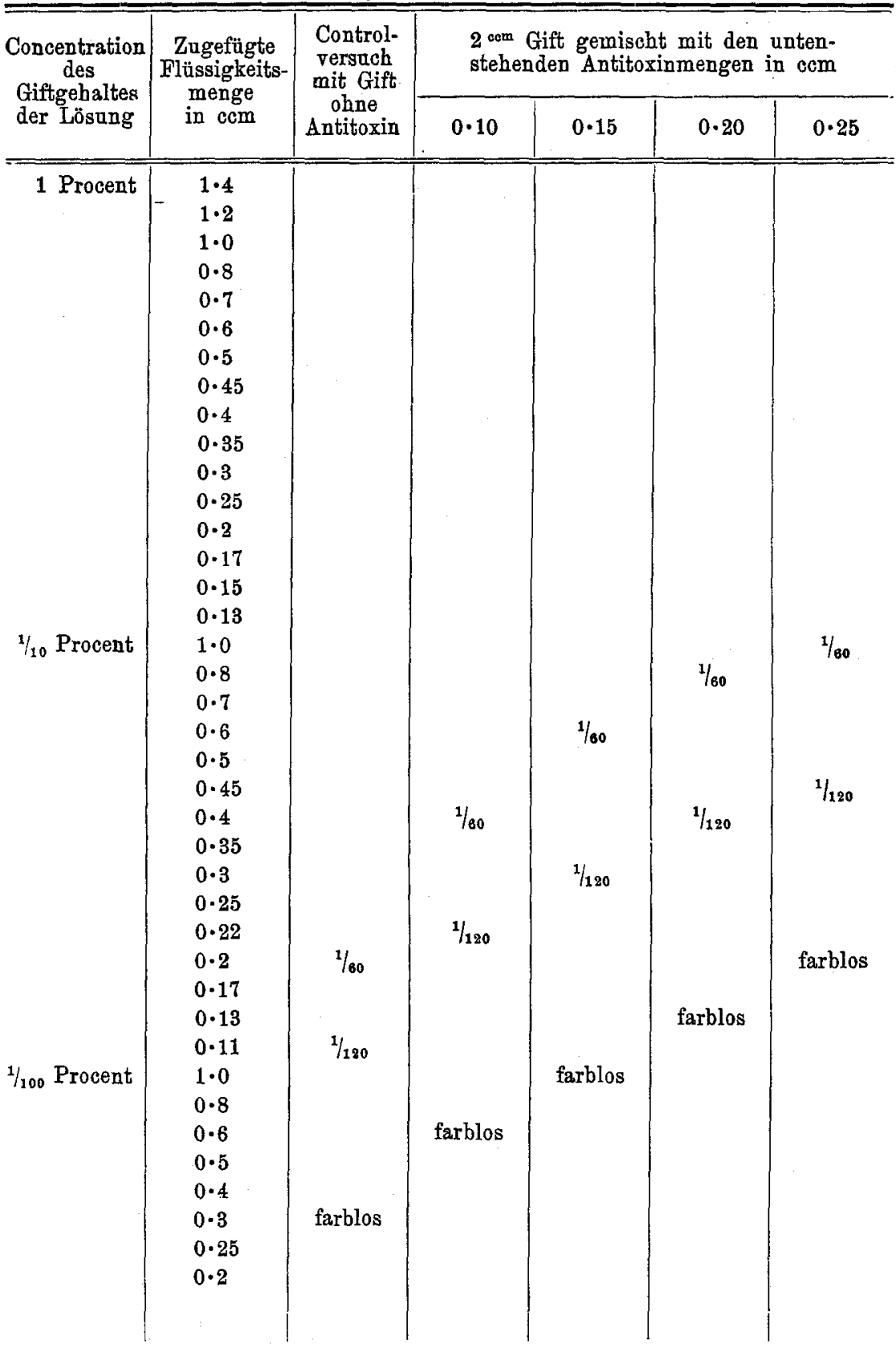


Über Tetanolysin.

Nach 24 Stunden.

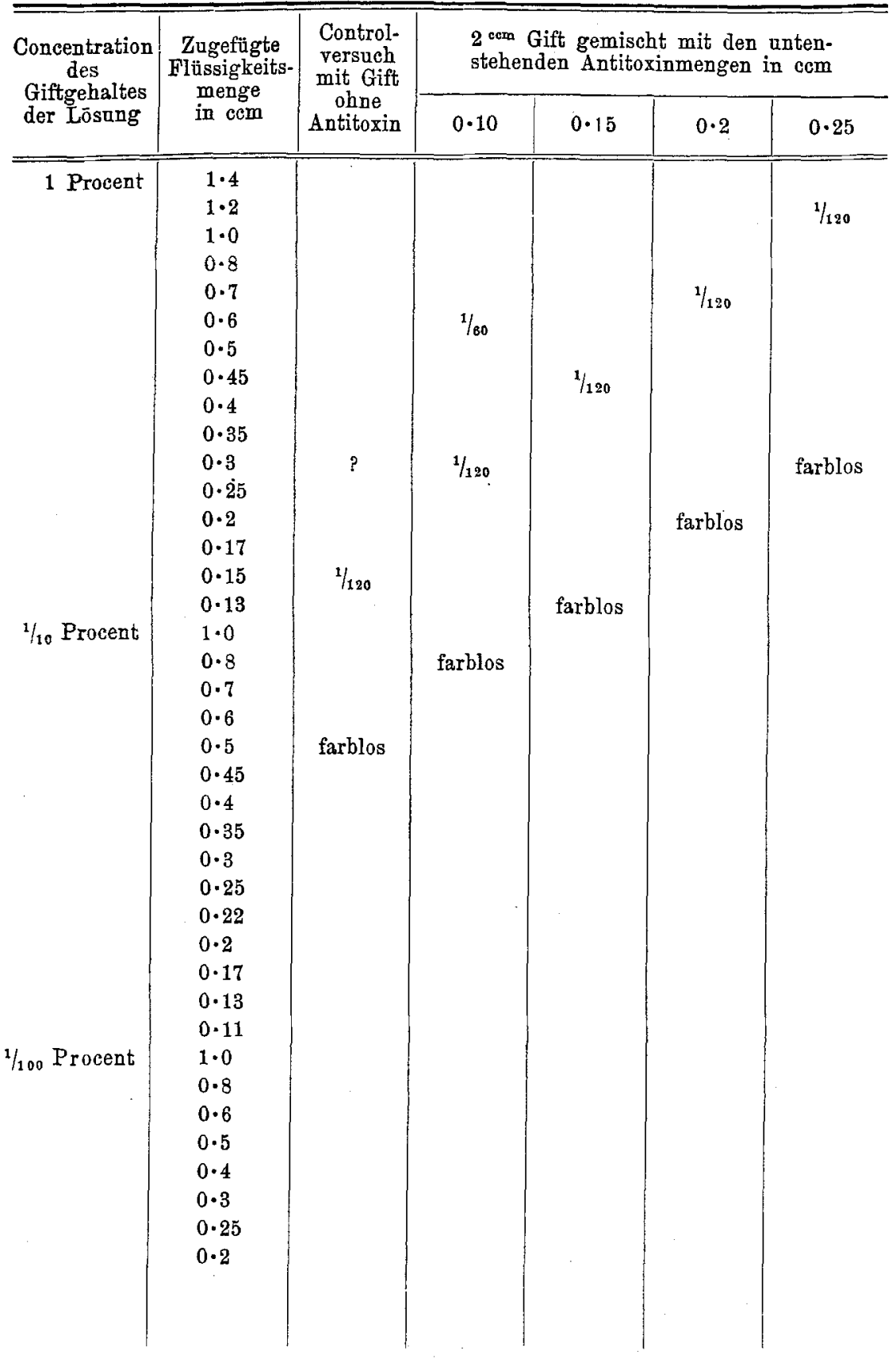




\section{Tabelle VII. Resumé.}

Nach $1 / 2$ Stunde.

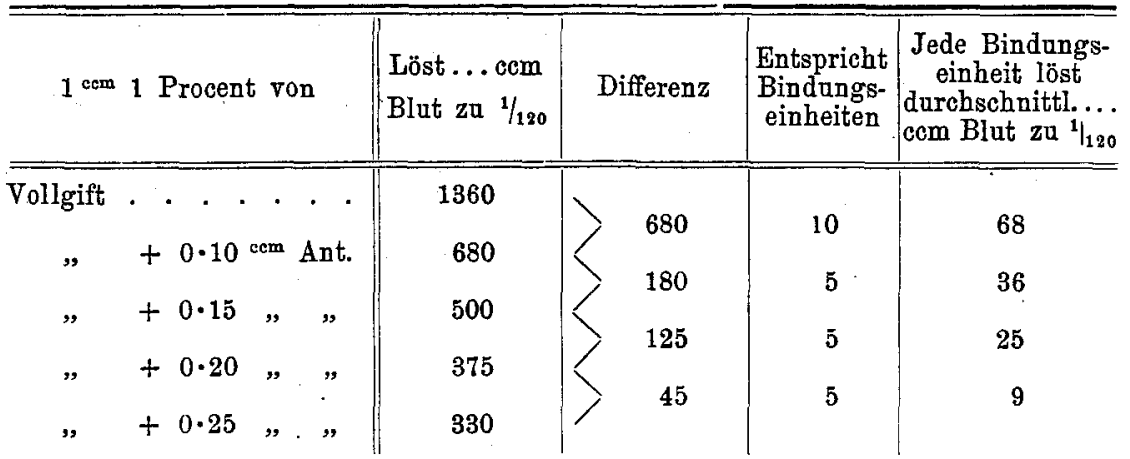

Nach 24 Stunden.

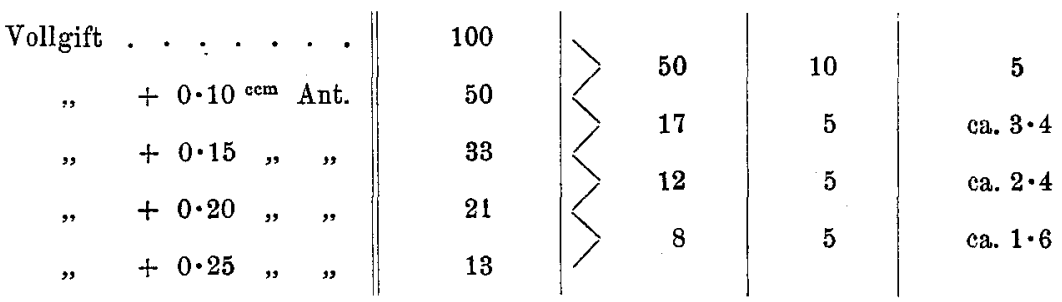
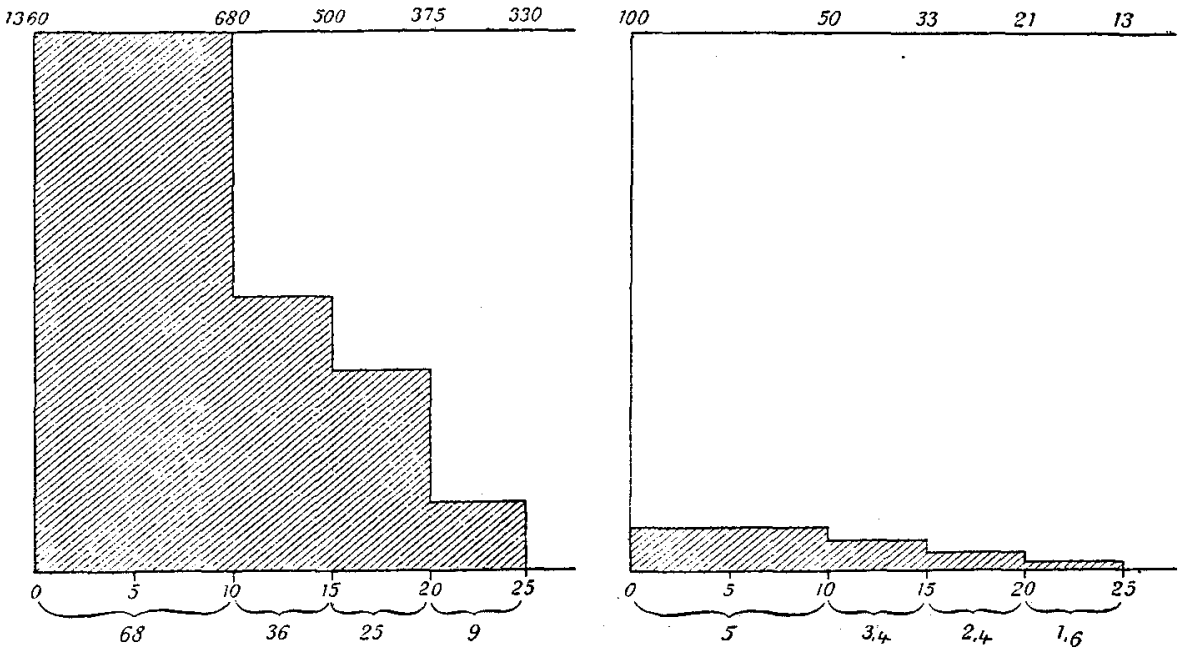

Die letzte Zahlenreihe entspricht der durchschnittl. Wirkung von jeder Bindungseinheit. Fig. 4. Fig. 5. 
Ich habe früher schon erwähnt, dass bei niedrigen Temperaturen die Wirkung des Tetanolysins eine bedeutend geringere ist. Dies ist keineswegs eine Eigenschaft aller hämolytischen Gifte." Vergleichende Versuche mit Sublimat und Crotin bei $0^{\circ}$ und $37^{\circ}$ ergeben, dass die Lösung der rothen Blutkörperchen freilich bedeutend langsamer in der Kälte als in der Wärme eintrat, dass aber nach 24 Stunden der Unterschied fast ganz ausgeglichen war, so dass die endgiltige Wirkung ungefähr dieselbe bei beiden Temperaturen war, gegenüber einem Verhältniss von $1: 100$ bei dem Tetanolysin. Wir müssen also einen wesentlichen Unterschied zwischen den hämolytischen Eig̈enschaften des Tetanolysins und der genannten Gifte aufstellen.

Auch die Wirkung der verschiedenen Theile des Tetanolysins verhält sich nicht gleichmässig in der Wärme und in der Kälte. Das Proto- und Deuterotoxin wirken bei allen Temperaturen; es zeigte sich in zahlreichen Versuchen, dass man in diesem Abschnitt immer das früher beschriebene Neutralisationsbild bei den verschiedensten Temperaturen zwischen $0^{\circ}$ und $37^{\circ}$ wiederfindet. Schalten wir durch Zufügung ron $0.25 \mathrm{~cm}$ Antoxinlösung das Proto- und Deuterotoxin aus, so verliert, wie früher erwähnt, das Gift ungefähr $9 / 10$ seiner Wirkung, so dass z. B. $0 \cdot 25$ cem $1 / 10$ Procent Vollgift bei $37^{\circ}$ dieselbe Wirkung hat wie $0.25 \mathrm{~cm} 1$ Procent von der genannten. Toxin-Antitoxinmischung. Nun kann man auch nachweisen, dass Tritotoxin und Toxon sich principiell anders verhalten, als der übrige Theil des Giftes. Bei Temperaturen unter $10^{\circ}$ vermögen nämlich selbst nicht die grössten Mengen des genannten ToxinAntitoxingemisches irgend welche Lösung hervorzubringen, z. B. $10^{\mathrm{cem}}$ 1 Procent Lösung bei $8^{\circ}$, während bei derselben Temperatur $0.5^{\mathrm{ccm}}$ $1 / 10$ Procent von Vollgift $\left(3:{ }^{1 / 200}\right)$ noch sehr deutliche Auflösung hervorruft. Erst bei $12^{\circ}$ bis $15^{\circ}$ beginnt die Lösung zuzunehmen, genau entsprechend der Temperaturerhöhung. Dem Tritotoxoid und Toxon fehlt also bei Temperaturen unter $10^{\circ}$ überhaupt jede bämolytische Wirkung.

Für dieses Verhalten kann man sich verschiedene Ursachen vorstellen.

1. Dass die toxophoren Gruppen des Wärme- und des Kältetoxins ${ }^{1}$ identisch sind, aber dass die des ersteren in der Kälte deshalb nicht zur Wirkung kommen, weil das Wärmetoxin bei niedriger Temperatur von den rothen Blutkörperchen nicht gebunden wird.

${ }^{1}$,Wärmetoxin“ ist die kurze Bezeichnung für eine Giftlösung, in der durch Zusatz von $0 \cdot 27 \mathrm{~cm}$ Antitoxin sicher alles Proto- und Deuterotoxin gesättigt ist, also alle Theile, die sowohl in der Wärme als in der Kälte wirken. Im Gegensatz hierzu ist Gift ohne Zusatz vou Antitoxin als „Kältetoxin“ bezeichnet. 
2. Dass die Bindung für die zwei Giftarten dieselbe wäre, dass aber die toxophoren Gruppen des Wärmetoxins schwächer sind, so dass sie nur bei Temperituren über $10^{\circ}$ zur Wirkung kommen, und

3. dass beide Möglichkeiten zutreffen.

Um dies zu untersuchen, wurde mehrmals folgender Versuch ausgeführt: Eine Reihe Centrifugengläschen, die $10 \mathrm{~cm}$ Blutmischung enthielten, wrurden durch Eiswasser gekühlt. Hierzu wurden die unten angegebenen Mengen, theils Wärme-, theils Kältetoxin zugesetzt und $11 / 2$ Stunden bei $0^{\circ}$ aufbewahrt. Dann wurde bei einer Temperatur von $-2^{0}$ centrifugirt. "Die obenstehende Flüssigkeit, die in allen Gläsern ganz wasserklar war, wurde abgegossen und die Blutkörperchen zweimal mit eisgekühlter physiologischer Kochsalzlösung gewaschen, um sicher die letzte Spur von nicht gebundenem Gift zu entfernen. Dann wurde wieder $10 \mathrm{~cm}$ physiologische Kochsalzlösung zugefügt, die Röhrchen 1 Stunde bei $37^{\circ}$ gehalten und nach 24 Stunden wurden die Farbennuancen beobachtet. Die Lōsung ist ein Ausdruck dafür, wieviel Gift von den rothen Blutkörperchen gebunden ist. (Vgl. Tab. VIII.)

Tabelle VIII.

\begin{tabular}{|c|c|c|c|c|c|}
\hline \multicolumn{3}{|c|}{ „Kältetoxin" } & \multicolumn{3}{|c|}{ „Wärmetoxin"s } \\
\hline \multicolumn{2}{|c|}{ Zugesetzte Giftlösung } & \multirow{2}{*}{$\begin{array}{c}\text { Auflösung } \\
\text { der Blut- } \\
\text { körperchen } \\
\text { nach } 24 \text { Std. }\end{array}$} & \multicolumn{2}{|c|}{ Zugesetzte Giftlösung } & \multirow{2}{*}{$\begin{array}{l}\text { Auflösung } \\
\text { der Blut- } \\
\text { körperchen } \\
\text { nach 24 Std }\end{array}$} \\
\hline Concentration & $\begin{array}{l}\text { Menge } \\
\text { in ccm }\end{array}$ & & Concentration & $\begin{array}{l}\text { Menge } \\
\text { in ccm }\end{array}$ & \\
\hline \multirow{9}{*}{$1 / 10$ Procent } & 0.8 & & 1 Procent & 3.0 & \\
\hline & 0.6 & & & $2 \cdot 5$ & \\
\hline & 0.5 & $1 / 180$ & & $2 \cdot 0$ & \\
\hline & 0.4 & & & $1 \cdot 75$ & \\
\hline & 0.3 & & & $1 \cdot 5$ & $1 / 160$ \\
\hline & 0.25 & farblos & & $1 \cdot 25$ & \\
\hline & 0.2 & & & 1.0 & \\
\hline & 0.17 & & & 0.8 & farblos \\
\hline & 0.13 & & & 0.6 & \\
\hline \multirow[t]{3}{*}{ 1/100 Procent } & $1 \cdot 0$ & & & 0.5 & \\
\hline & 0.8 & & & 0.4 & \\
\hline & 0.6 & & & 0.3 & \\
\hline
\end{tabular}

Wie ersichtlich, muss man, damit dieselbe Menge gebunden werden kann, nahezu $30 \mathrm{Mal}$ soviel Wärme- als Kältetoxin anwenden. Da 10 Theile von dem ersteren bei $37^{\circ}$ einem Theile des letzteren entsprechen, sieht man, dass bei $0^{\circ}$ dreimal weniger Wärmetoxin als Kältetoxin gebunden wird. Es wird also auch in der Kälte das Wärmetoxin 
zwar thatsächlich gebunden, aber dreimal weniger als Kältetoxin. Hieraus ist ersichtlich, dass die toxophore Gruppe des Wärmetoxins von anderer Art als die des Kältetoxins sein muss. Wären sie identisch, müsste man durch Anwendung von 30 Mal so viel Wärmetoxin als Kältetoxin in der Kälte dieselbe Wirkung hervorbringen können. Dies ist aber nicht der Fall, selbst nicht durch Anwendung der 200 fachen Menge bekommt man irgend welche Wirkung.

Tabelle IX.

$2^{\mathrm{ccm}} 4$ proc. Tetanolysinlösung werden mit $0.15^{\mathrm{cm}} 1 / 20$ proc. Antitoxinlösung gemischt. Sie stehen dann unter angeführten Zeiten bei ca. $15^{0}$, werden darnach zur angegebenen Giftconcentration verdünnt und zum Blut abgemessen.

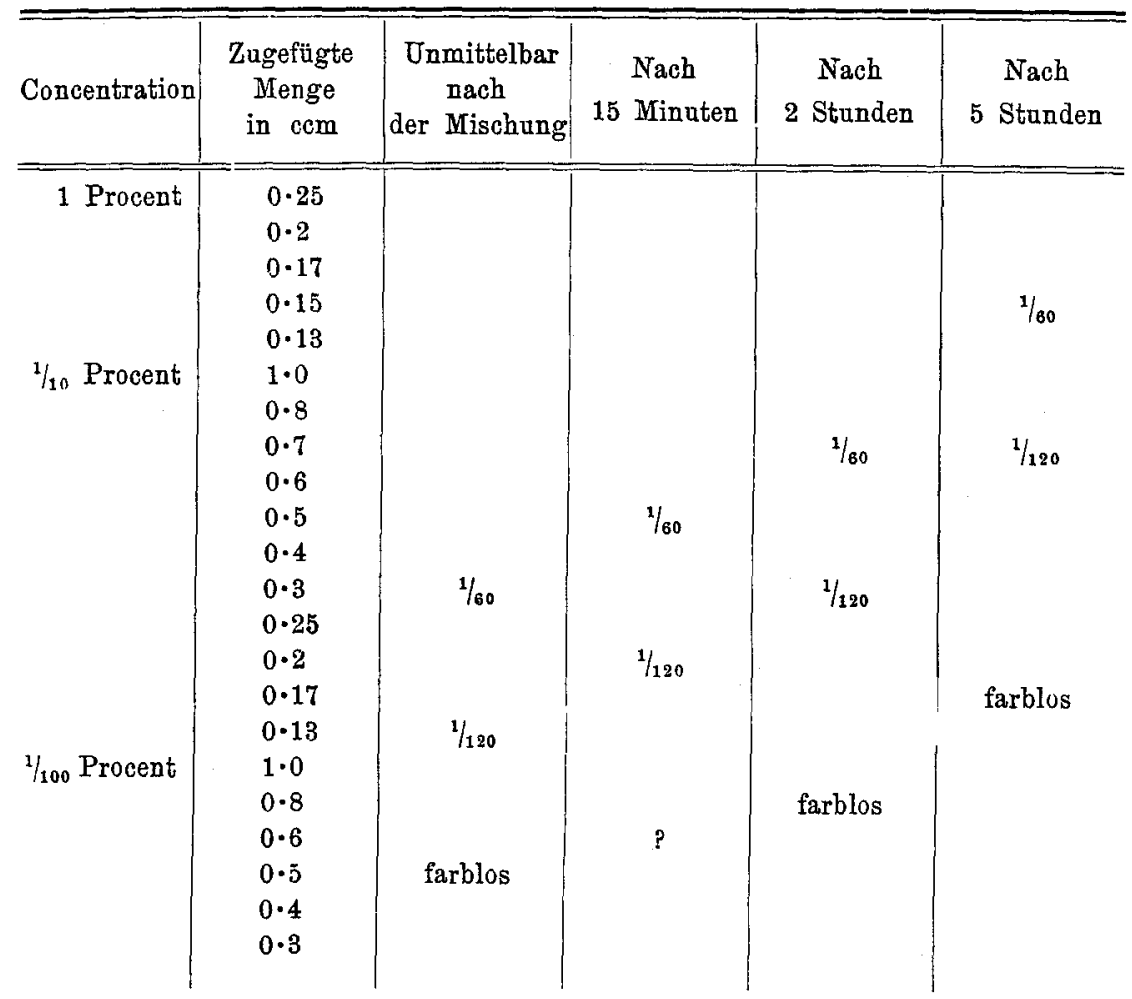

Alle die erwähnten Versuche erlauben keinen Zweifel, dass eine chemische Bindung zwischen dem Tetanolysin und dem entsprechenden Antikörper besteht. Wie Ehrlich zuerst aussprach, gelten für diese Bindung (Diphtheriegift, Tetanospasmin) die allgemein giltigen Gesetze. Man 
kann z. B. leicht für das Tetanolysin nachweisen, dass die Zeit eine grosse Rolle spielt, indem es ziemlich lange dauert, bis die Reaction vollendet ist. Darin steht das Tetanolysin im Gegensatz zum Diphtheriegift, wo die Reaction zwischen Toxin und Antitoxin in kurzer Zeit vollendet ist. Dies ist aus vorstehendem Beispiel ersichtlich: (Vgl. Tab. IX.)

Gleichzeitige Versuche zeigten, dass das Gift im Laufe der ersten 2 Stunden nicht abgeschwächt wurde, wohl aber im Laufe der nächsten 3 Stunden sich um die Hälfte abschwächt.

Man sieht aus der Tabelle, dass sofort nach der Mischung die Componenten nicht rollständig vereinigt sind; auch nach 15 Minuten ist das noch nicht der Fall. Nach 2 Stunden scheint die Reaction fast vollendet zu sein; es geht aus Tabelle IV hervor, dass hierzu vielleicht schon eine noch geringere Zeit (30 Minuten) ausreichen dürfte. Die angeführten Zahlen lehren deutlich, welche Versuchsfehler man vermeiden muss, wenn man mit Tetanolysin arbeitet. Einerseits muss man dafür sorgen, dass die Bindung zwischen Gift und Antitoxin so vollständig als möglich wird, auf der anderen Seite, dass das Gift sich nicht abschwächt. Eine der wichtigsten Regeln bei diesen Arbeiten ist also, dass die Versuche gleichzeitig gemacht werden.

Bei einer nicht eingehenden Untersuchung eines anderen mit $\left(\mathrm{NH}_{4}\right)_{2} \mathrm{SO}_{4}$ ausgefällten Giftes wurden fast dieselben Verhältnisse wie bei dem eben beschriebenen Gift gefunden, so dass man eine Proto-, Deuteround Tritotoxin- sowie eine Toxonzone unterscheiden konnte. Auch hier konnte man den Unterschied zwischen „Wärme-“ und „Kälte“toxin nachweisen.

Wollen wir die Resultate unserer Versuche zusammenfassen, so können wir Folgendes sagen:

In den Culturen des Tetanusbacillus findet sich ein von dem Tetanospasmin verschiedenes Gift, das Tetanolysin, für welches ein specifisches Antitoxin, das Antilysin, besteht.

Die Wirksamkeit dieses Lysins und seines Antikörpers lässt sich durch einfache Methoden der Farbenvergleichung mit grosser Genauigkeit messen.

Das Tetanolysin*wird von den rothen Blutkörperchen gebunden, und diese werden nach einer gewissen Latenzzeit, die von der Giftmenge und der Temperatur abhängt, gelöst.

Eine eingehende Untersuchung lehrt, dass dem Tetanolysin ein complicirtes Neutralisationsbild zukommt, das eine grosse Uebereinstimmung mit dem des Diphtheriegiftes, wie das Ehrlich festgestellt hat, 
zeigt. Wie beim Diphtheriegift kann man auch bei dem Tetanolysin durch partielle Sättigung eine ganze Reihe von Bestandtheilen aussondern, die eine verschiedene Wirksamkeit besitzen.

Theilt man das Gift in zwei Hälften, so kann man zwei fundamental verschiedene Theile unterscheiden. Den ersten Theil des Giftes kann man in drei Gruppen sondern: Prototoxin, Deuterotoxin und Tritotoxin.

Das Prototoxin macht nur den 13. Theil unseres Giftes aus und ist der Träger der Hälfte der gesammten Lösungsfähigkeit. Ebenso wie das Prototoxin des Diphtheriegiftes unterliegt auch dieses sehr leicht der Abschwächung und wird zum Prototoxoid umgebildet oder in anderen Worten: es vermindert seine Giftigkeit und behält seine Bindungsfähigkeit unverändert bei.

Dem Deuterotoxin, das den 9. Theil unseres Giftes bildet, kommen etwa $2 / 5$ der totalen Giftwirkung zu; mit dem Denterotoxin des Diphtheriegiftes theilt es die verhältnissmässige Resistenz gegenüber äusseren Einwirkungen.

Das Tritotoxin endlich, das etwa $1 / 4$ des Giftes bildet, ist von sehr geringer Wirkungsfähigkeit, die etwa den 10. Theil der Totalwirkung des Giftes darstellt. Während das Proto- und Deuterotoxin sowohl bei höherer als auch bei niedriger Temperatur wirkt, war das Tritotoxin ganz ausser Stande, bei Temperaturen unter $10^{\circ}$ in Wirksamkeit zu treten. Besonders darauf gerichtete Versuche zeigten, dass das Tritotoxin nicht allein in geringerem Maasse als die beiden anderen Toxine von den rothen Blutkörperchen gebunden wird, sondern namentlich, dass deren toxophore Gruppe von viel schwächerer Wirkung war, als die des Proto- und Deuterotoxins.

Etwa die zweite Hälfte des Giftes besitzt eine überaus geringe Giftigkeit. Sein Verhalten erinnert an das des frischen Diphtheriegiftes, wo man auch in der einen Hälfte des Giftes Componenten von principiell verschiedener Art trifft. Wir wählen deshalb auch für diesen Bestandtheil des Tetanolysins die Bezeichnung Toxon.

Als wichtiges Resultat unserer Ontersuchungen ergiebt sich, dass wir beim Tetanolysin ebenso wie beim Diphtheriegift das Vorhandensein zweier verschiedener Gruppen annehmen müssen, eine haptophore (antitoxinbindende) und eine toxophore (Träger der hämolytischen Fähigkeit). Von diesen ist die erstere relativ stabil, während die letztere sehr leicht zerstört oder modificirt wird, ein Vorgang, der in der "Toxoidbildung"6 seinen Ausdruck findet.

Aller Wahrscheinlichkeit nach kommt dem Tetanospasmin ein ähnliches Neutralisationsbild zu, wie dem Tetanolysin. Nach Versuchen, die Dr. J. Morgenroth im Institut ausgeführt hat, liess sich sagen, dass 
in dem lege artis entworfenen "Giftspectrum" Tritotoxoidzone und ein ausgedehntes Toxongebiet sicher enthalten sind. Einer genauen Analyse des Tetanospasmins stellen sich grosse Schwierigkeiten entgegen, indem die unerlässlich sichere Basis, die tödtliche Dose, nicht mit der nöthigen Genauigkeit zu bestimmen ist.

Man sieht, wie viel günstiger die Verhältnisse bei den hier beschriebenen Reagensglasversuchen liegen. Man ist jederzeit in der Lage, beliebig viele Versuche gleichzeitig auszuführen und alle Experimente auf Controlversuche zu beziehen, die unter ganz gleichen Bedingungen und mit einem Versuchsobjecte von jeweils absolut gleichartiger Empfindlichkeit ausgeführt sind. Besonders bei Giften labilster Art, wie das Tetanolysin, bietet nur der Reagensglasversuch volle Gewähr, dass nicht uncontrolirbare Abschwächungen und Veränderungen des Giftes die Versuchsresultate trüben.

Auch das scheinbar so einfache 0 bject dieses Reagensg las versuches erscheint bei genauerer Betrachtung nicht ohne Interesse und complicirter, als man ursprünglich erwartete. Muss man doch nach aller Wahrscheinlichkeit annehmen, dass jedes Blutkörperchen eine ihm eigenthümliche Empfindlichkeit dem Tetanolysin gegenüber hat, eine Eigenschaft, die demselben nicht etwa in ganz gleicher Weise anderen blutlösenden Giften gegenüber zukommt. Man kann nicht von einem gewissen Empfindlichkeitsgrad des Blutes als Ganzem überhaupt sprechen, sondern man hat stets ein Gemenge von scheinbar gleichartigen, thatsächlich aber auf verschiedene Eingriffe reeht verschieden reagirenden Elementen vor sich. Wenn schon ein so einfaches Versuchsobject, wie eine Aufschwemmung von rothen Blutkörperchen in physiologischer Kochsalzlösung, sich im Grunde als recht complicirt erweist, so lässt dies einen Schluss zu, unter wie complicirten Bedingungen sich die Wirkungen eines Giftes im Thierkörper mit seinen mannigfaltigen Zellcomplexen abspielen. 